\title{
Factors influencing the career interest of medical graduates in obstetrics and gynaecology in Hong Kong: a cross-sectional questionnaire survey
}

\author{
Christy YY Lam *, Charleen SY Cheung, Annie SY Hui
}

\section{A B S T R A C T}

Introduction: The trend of declining interest of medical graduates in pursuing obstetrics and gynaecology as a career has been observed in many overseas studies. This study aimed to evaluate the career interest of the most recent medical graduates in Hong Kong, especially their level of interest in obstetrics and gynaecology, and to identify key influential factors for career choice and career interest in obstetrics and gynaecology.

Methods: All medical graduates from the Chinese University of Hong Kong and the University of Hong Kong who attended the pre-internship lectures in June 2015 were invited to participate in this crosssectional questionnaire survey. The main outcome measures were the level of career interest in obstetrics and gynaecology, the first three choices of specialty as a career, key influential factors for career choice, and key influential factors for career interest in obstetrics and gynaecology.

Results: Overall, $73.7 \%$ of 323 new medical graduates participated in the study and 233 questionnaires were analysed. The median score (out of 10) for the level of career interest in obstetrics and gynaecology was 3 . There were $37(16.2 \%)$ participants in whom obstetrics and gynaecology was among their first three choices, of whom 29 (78.4\%) were female. Obstetrics and gynaecology ranked as the eighth most popular career choice. By factor analysis, the strongest key influential factor for career interest in obstetrics and gynaecology was clerkship experience (variance explained 28.9\%) and the strongest key influential factor for career choice was working style (variance explained 26.4\%).

Conclusions: The study confirmed a low level of career interest in obstetrics and gynaecology among medical graduates and a decreasing popularity of the specialty as a career choice. The three key influential factors for career interest in obstetrics and gynaecology and career choice were working style, clerkship experience, and career prospects.

\section{Hong Kong Med J 2016;22:138-43 DOI: $10.12809 / \mathrm{hkmj} 154650$

\author{
${ }^{1}$ CYY Lam *, MB, BS \\ ${ }^{3}$ ASY Hui, MB, BS, FHKAM (Obstetrics and Gynaecology)
} \\ ${ }^{2}$ CSY Cheung, MB, BS, FHKAM (Obstetrics and Gynaecology)}

\section{Department of Obstetrics and Gynaecology, Pamela Youde Nethersole Eastern Hospital, Chai Wan, Hong Kong \\ Department of Obstetrics and Gynaecology, Queen Mary Hospital, The University of Hong Kong, Pokfulam, Hong Kong \\ Department of Obstetrics and Gynaecology, Prince of Wales Hospital, \\ The Chinese University of Hong Kong, Shatin, Hong Kong}

* Corresponding author: christylamyy@gmail.com

New knowledge added by this study

- Career interest in obstetrics and gynaecology (O\&G) was low among current medical graduates in Hong Kong.

- Medicine and surgery remained the most popular career choices among current medical graduates in Hong Kong.

- The key influential factors in career choice were working style, clerkship experience, and career prospects.

Implications for clinical practice or policy

- Review of the training and working conditions of O\&G doctors with regard to compatibility with a work-life balance should be undertaken to improve the competitiveness of $O \& G$ as a career choice.

- Quality of clerkship experience, including interaction with O\&G doctors and nurses, should be assured to improve medical graduates' career interest in O\&G.

\section{Introduction}

In Hong Kong, career opportunities in obstetrics and gynaecology $(O \& G)$ for medical graduates have undergone a roller-coaster ride over the last two decades. For O\&G, the number of new trainees per year in the territory dropped from 11 in 2000 to a trough of five in 2004, followed by a steep rise to 22 in 2006. ${ }^{1}$ This trend was driven by multiple factors, notably the local birth rate and the influx of noneligible person deliveries during this period.

According to the discussion paper 'Manpower requirement and strategies for doctors' published by the Hospital Authority in 2010, the annual intake requirement of $O \& G$ doctors was projected to be 20 for the period 2010 to $2016 .{ }^{2}$ Recruitment of O\&G resident trainees in the latest Annual Recruitment 
Exercise in 2015 was unexpectedly difficult, however. Among the 24 O\&G resident trainee posts available in the Annual Recruitment Exercise for Resident Trainees $2015 / 16,{ }^{3}$ less than $50 \%$ were filled by May 2015 and 11 posts remained vacant in July $2015,{ }^{4}$ thus creating a manpower crisis in $O \& G$.

The trend of declining interest of medical graduates in pursuing $O \& G$ as a career has likewise been observed in overseas studies ${ }^{5,6}$ with various factors explored, such as perception of $O \& G$ clerkship,,$^{5-7}$ lifestyle, ${ }^{5,7}$ gender, ${ }^{5,7,8}$ and medicolegal issues., Local data on this topic are lacking. A literature search revealed one local study on specialty choice of medical graduates was conducted 20 years ago $^{9}$ and another focused on the specialty of family medicine. ${ }^{10}$ In view of the recent manpower crisis, there was an urgent need to perform a study on this topic as it might guide manpower planning and formulation of solutions.

The objectives of this study were to evaluate the career interest of the most recent medical graduates in Hong Kong, especially their level of career interest in $O \& G$, and to identify key influential factors for career choice and career interest in $O \& G$.

\section{Methods}

This was a cross-sectional questionnaire survey. All medical graduates of the University of Hong Kong (HKU) and the Chinese University of Hong Kong (CUHK), who graduated in 2015 and attended the pre-internship lectures held in their medical school on 5 and 8 June 2015 respectively, were invited to participate. This study was approved by the Institutional Review Board of the University of Hong Kong / Hospital Authority Hong Kong West Cluster and the Joint Chinese University of Hong KongNew Territories East Cluster Clinical Research Ethics Committee.

All medical graduates who attended the lectures were given an information sheet and consent form. Those who consented were invited to complete a self-administered anonymous questionnaire in English that was collected on the same day by the investigator.

The questionnaire comprised 14 questions in three sections: (1) demographic data, (2) current view on career choice, and (3) view on O\&G as a career. The second section explored the first three choices of specialty as a career and the extent of influence of 28 items on career choice. The third section evaluated the current level of career interest in $O \& G$, the extent of influence of 28 items on career interest in $O \& G$, and the impact on the level of career interest in O\&G of five possible changes. The 28 items were potential influential factors that were identified from overseas studies ${ }^{5-8}$ in the following categories: (1) ability, interest, and personality, (2) clerkship experience, (3) influence of family, peers,

\section{香港醫科畢業生選擇入職婦產科的影響因素： 橫斷面問卷調查 \\ 林瑜玉、張士恩、許淑儀}

目的：很多海外研究均發現醫科畢業生對於入職婦產科的意欲下降。 本研究旨在評估香港最新一屆醫科畢業生入職專科的選擇（尤其是對 入職婦產科的興趣），以及影響他們選擇入職任何專科和選擇入職婦 產科的關鍵因素。

方法：這橫斷面問卷調查的對象為參與2015年6月舉辦的實習前講課 的所有香港中文大學和香港大學醫科畢業生。主要結果為受訪者對入 職婦產科的興趣水平、首三項選擇入職的專科、選擇入職任何專科的 關鍵影響因素，以及選擇入職婦產科的關鍵影響因素。

結果：323名新一屆醫科畢業生中有 $73.7 \%$ 參與是項問卷調查, 最終 分析了 233 份問卷。以 10 分為滿分, 入職婦產科的興趣水平中位數為 3 分。37名 ( $16.2 \%)$ 受訪者的首三項專科選擇包括婦產科, 當中 $29 人$ ( $78.4 \%)$ 為女性。最受歡迎的專科中, 婦產科排名第八。通過因子 分析, 選擇入職婦產科的最關鍵影響因素為臨床學習經驗 (方差解釋 $28.9 \%$ ），而選擇入職任何專科的最關鍵影響因素為工作模式（方差 解釋 $26.4 \%$ ）。

結論：是項研究證實醫科畢業生對於入職婦產科的意欲低, 而且婦產 科的受歡迎程度正在下降。工作模式、臨床學習經驗和職業前景均為 選擇入職婦產科的關鍵影響因素。

and seniors, (4) medicolegal issues, (5) nature of the specialty, (6) other experience related to the specialty, (7) career prospects, (8) religion, and (9) training and working conditions.

All statistical analyses were performed using PASW Statistics 18, Release Version 18.0.0 (SPSS Inc., 2009, Chicago [IL], US). Categorical data were presented as counts and percentages. Continuous data were expressed as median (interquartile range) as they were highly skewed. Chi squared test and Fisher's exact test were used to compare categorical data. For continuous data, as they were highly skewed, a nonparametric test (Mann-Whitney $U$ test or KruskalWallis $\mathrm{H}$ test) was used. Results with a $\mathrm{P}$ value of $<0.05$ were considered statistically significant.

In order to investigate the structure of the potential factors influencing career choice and career interest in $O \& G$, an exploratory factor analysis by the extraction method of principal component analysis with varimax rotation was performed. An exploratory factor analysis was performed instead of a confirmatory factor analysis because the factor structure was uncertain. The number of factors to be extracted was based on the result from the scree-plots and the Kaiser's eigenvalue criterion (eigenvalue $>1$ ). Missing values were excluded listwise. The quality of the factor analysis models was assessed by Bartlett's test of sphericity and the Kaiser-Meyer-Olkin (KMO) measure of sampling adequacy.

\section{Results}

In June 2015, there were 323 new medical graduates 
in Hong Kong, of whom 163 were from HKU and 160 were from CUHK. Among them, 283 attended the pre-internship lectures (157 HKU graduates and 126 CUHK graduates); 238 participants were recruited who constituted $73.7 \%$ of all 323 medical graduates and $84.1 \%$ of 283 medical graduates in the lectures. Five questionnaires were excluded from analysis due

TABLE I. Demographic data of participants

\begin{tabular}{lc}
\hline Demographics & $\begin{array}{c}\text { Median (interquartile range) or } \\
\text { No. (\%) of participants }\end{array}$ \\
\hline Age & $23(23-24)$ \\
\hline Gender & $122(52.4 \%)$ \\
Female & $111(47.6 \%)$ \\
\hline Male & $226(97 \%)$ \\
Marital status & $6(2.6 \%)$ \\
\hline Single & $1(0.4 \%)$ \\
\hline Engaged & $233(100 \%)$ \\
\hline Married & $100(42.9 \%)$ \\
No. of children & $133(57.1 \%)$ \\
\hline Zero & \\
University & \\
CUHK & \\
HKU & \\
\hline Abbreviations: CUHK = The Chinese University of Hong Kong; \\
HKU = The University of Hong Kong
\end{tabular}

to significant missing data (four missing the level of career interest in $O \& G$ and one missing the extent of influence of factors for career interest in $O \& G$ ). Thus, 233 questionnaires were analysed.

Table 1 shows the demographic data of participants. There were 229 (98.3\%) participants who planned to undergo specialty training after internship. Table 2 shows the distribution of their first three choices of specialty. There were 13 (5.7\%) participants who indicated O\&G as their first choice of specialty and $37(16.2 \%)$ participants who listed O\&G among their first three choices of specialty, of whom 29 (78.4\%) were female and eight (21.6\%) were male.

On a scale of 1 (nointerest at all) to 10 (extremely interested), the median (interquartile range) score for the current level of career interest in $O \& G$ was 3 (1-6). The association between demographics and level of career interest in O\&G is shown in Table 3. Gender was significantly associated with level of career interest in $O \& G$ with females more interested than males. There was also a statistically significant association between gender and listing O\&G among the first three choices of specialty $(\mathrm{P}=0.001)$.

In the exploratory factor analysis, the values of KMO measure of sampling adequacy were $>0.6$. The $\mathrm{P}$ values of Bartlett's test of sphericity were both $<0.05$. These figures indicated that the use of factor analysis was appropriate to investigate the underlying factors in this study. Eight underlying

TABLE 2. First three choices of specialty as a career

\begin{tabular}{lcccc}
\hline Specialty* & \multicolumn{4}{c}{ No. (\%) of participants } \\
\cline { 2 - 5 } & First three choices combined & First choice & Second choice & Third choice \\
\hline Medicine & $125(54.6)$ & $53(23.1)$ & $42(18.3)$ & $30(13.1)$ \\
\hline Surgery & $72(31.4)$ & $43(18.8)$ & $17(7.4)$ & $12(5.2)$ \\
\hline Paediatrics & $67(29.3)$ & $24(10.5)$ & $18(7.9)$ & $25(10.9)$ \\
\hline Family Medicine & $65(28.4)$ & $8(3.5)$ & $22(9.6)$ & $35(15.3)$ \\
\hline Emergency Medicine & $64(27.9)$ & $13(5.7)$ & $26(11.4)$ & $25(10.9)$ \\
\hline Anaesthesiology & $47(20.5)$ & $15(6.6)$ & $20(8.7)$ & $12(5.2)$ \\
\hline Orthopaedics & $39(17.0)$ & $15(6.6)$ & $17(7.4)$ & $7(3.1)$ \\
\hline Obstetrics and Gynaecology & $37(16.2)$ & $13(5.7)$ & $12(5.2)$ & $12(5.2)$ \\
\hline Clinical Oncology & $36(15.7)$ & $9(3.9)$ & $12(5.2)$ & $15(6.6)$ \\
\hline Psychiatry & $34(14.8)$ & $16(7.0)$ & $8(3.5)$ & $10(4.4)$ \\
\hline Radiology & $18(7.9)$ & $3(1.3)$ & $8(3.5)$ & $7(3.1)$ \\
\hline Otorhinolaryngology & $14(6.1)$ & $1(0.4)$ & $6(2.6)$ & $7(3.1)$ \\
\hline Ophthalmology & $13(5.7)$ & $8(3.5)$ & $4(1.7)$ & $1(0.4)$ \\
\hline Pathology / Microbiology & $10(4.4)$ & $3(1.3)$ & $4(1.7)$ & $3(1.3)$ \\
\hline Community Medicine & $4(1.7)$ & $0(0)$ & $0(0)$ & $4(1.7)$ \\
\hline Intensive Care Medicine & $3(1.3)$ & $0(0)$ & $2(0.9)$ & $1(0.4)$ \\
\hline Missing data & $39(17.0)$ & $5(2.2)$ & $11(4.8)$ & $23(10)$ \\
\hline
\end{tabular}

* Specialty in the order of popularity when the first three choices are combined 
TABLE 3. Association between demographics and level of career interest in O\&G

\begin{tabular}{cccc}
\hline Demographics & No. & $\begin{array}{c}\text { Level of interest } \\
\text { in O\&G* }\end{array}$ & P value \\
\hline $\begin{array}{c}\text { Gender } \\
\text { Female }\end{array}$ & 122 & $4(2-7)$ & $<0.001$ \\
Male & 111 & $2(1-4)$ & \\
University & & & 0.058 \\
CUHK & 100 & $3(1-5)$ & \\
\hline HKU & 133 & $3(2-7)$ & \\
\hline
\end{tabular}

Abbreviations: CUHK = The Chinese University of Hong Kong; $\mathrm{HKU}=$ The University of Hong Kong; $O \& G=$ obstetrics and gynaecology

* Median (interquartile range) is shown, and the data were analysed by Mann-Whitney $U$ test or Kruskal-Wallis $\mathrm{H}$ test

factors were extracted for career choice and seven underlying factors were extracted for career interest in O\&G. All had an eigenvalue of $>1$, implying that these factors were meaningful. The total percentage of variance explained by the eight underlying factors for career choice and that for the seven underlying factors for career interest in O\&G were both $68.0 \%$, meaning these factors could explain $68.0 \%$ of the condition.

The three factors with the highest percentage of variance explained were identified as the key influential factors. The key influential factors for career choice and career interest in O\&G are shown in Table 4.

Comparison of gender with the median of key influential factors for career choice and career interest in $O \& G$ revealed no difference except for clerkship experience. This was the strongest key influential factor for career interest in O\&G. The median rating by female participants was 21 (18-24) and that for male participants was 19 (16-22) $[\mathrm{P}=0.021]$.

Impact on career interest in $O \& G$ of five potential changes was evaluated (Fig). Decreasing the frequency of on-call duty and better remuneration had the highest positive impact. The option of parttime training with a longer training period had the lowest positive impact but highest negative impact.

\section{Discussion}

To our knowledge, this is the first study in Hong Kong to investigate the career interest of medical graduates in $O \& G$ and the influential factors. It was satisfactory to have a participation rate of $73.7 \%$ of the 323 medical graduates in Hong Kong this year.

Medicine and surgery were the most popular specialty choices. This is consistent with previous local studies. ${ }^{9,10}$ On the other hand, O\&G ranked eighth when combined with the first three choices and sixth as the first choice. This is a reduction from previous local studies in which its popularity was ranked as third ${ }^{9}$ and fourth ${ }^{10}$, respectively.

The level of career interest in O\&G was low with a median score of 3 (out of 10). Female participants had a higher career interest in O\&G than their male counterparts, which is consistent with overseas studies. ${ }^{8}$

The key influential factors for career choice and career interest in $O \& G$ were consistent, namely clerkship experience, working style, and career prospects.

Working style was the strongest key influential factor for career choice, with the highest percentage of variance explained (26.4\%). The items included in this factor had a similar coefficient of around 0.8 , reflecting that each item made a similar contribution to this factor. This factor was important to both female and male medical graduates with no statistically significant gender difference. The focus on a work-life balance has attracted increasing attention, not just locally but globally, and is not unique to the medical profession. There were 149 (63.9\%) participants who considered a decreased on-call frequency would have a positive impact on their level of interest in O\&G. This had the highest positive impact among the five possible changes explored. Efforts should be made to avoid the vicious cycle of lack of manpower and increased on-call frequency in order to maintain the attractiveness of $O \& G$ to future generations of the profession. In addition, providing better remuneration, such as a special honorarium for extra on-call duties, might be explored, especially when manpower is insufficient. This was thought to increase career interest in $O \& G$ by $141(60.5 \%)$ participants.

Clerkship experience was the strongest key

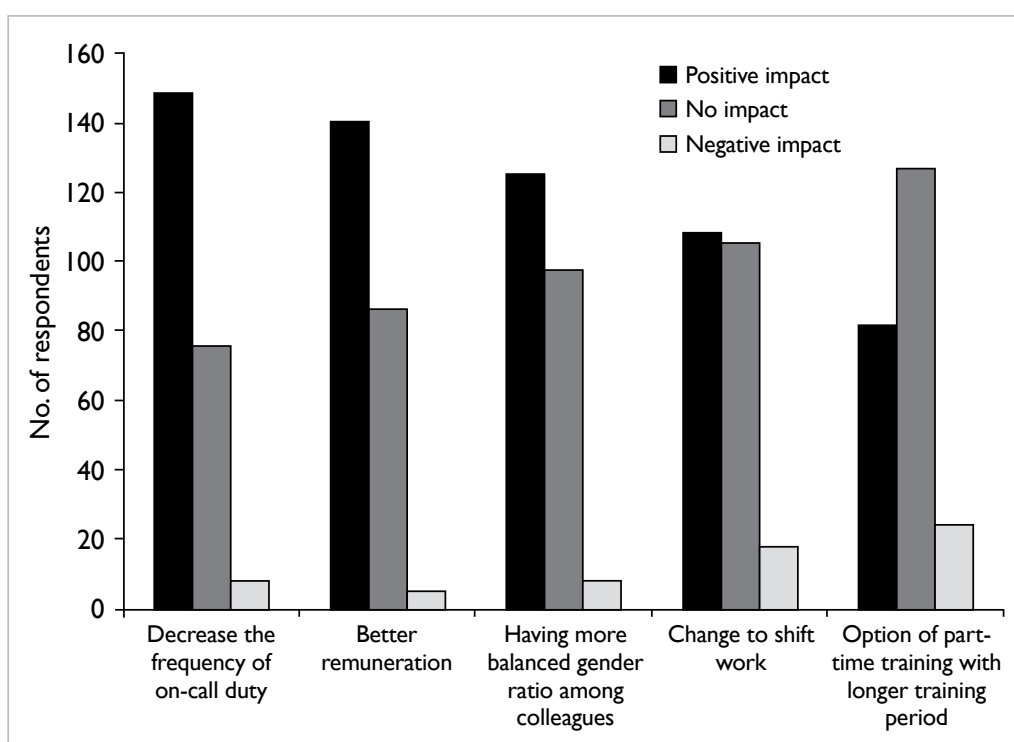

FIG. Impact on career interest in obstetrics and gynaecology from potential changes 
TABLE 4. Key influential factors for career choice and for career interest in obstetrics and gynaecology (O\&G) by exploratory factor analysis

\begin{tabular}{|c|c|c|c|}
\hline Key influential factor & Coefficient & Eigenvalue & $\begin{array}{c}\text { Variance } \\
\text { explained (\%) }\end{array}$ \\
\hline \multicolumn{4}{|l|}{ For career choice* } \\
\hline Factor 1: working style & & 7.39 & 26.394 \\
\hline Regularity of working hours & 0.878 & & \\
\hline On-call frequency & 0.871 & & \\
\hline Compatibility of work-life balance & 0.855 & & \\
\hline No. of years of on-site call & 0.842 & & \\
\hline Factor 2: clerkship experience & & 3.101 & 11.076 \\
\hline Encounter with role-model specialists/consultants/professors & 0.809 & & \\
\hline Encounter with role-model resident trainees & 0.749 & & \\
\hline Working atmosphere of the specialty observed during clerkship & 0.695 & & \\
\hline Learning experience in lectures/clerkship & 0.674 & & \\
\hline Factor 3: career prospects and medicolegal issues & & 2.228 & 7.958 \\
\hline Cost of professional indemnity & 0.865 & & \\
\hline Risk of litigation & 0.841 & & \\
\hline Level of respect in society & 0.711 & & \\
\hline Prospect for promotion or in private sector & 0.443 & & \\
\hline \multicolumn{4}{|l|}{ For career interest in $\mathrm{O} \& \mathrm{G} \dagger$} \\
\hline Factor 1: clerkship experience & & 8.095 & 28.912 \\
\hline Overall learning experience in O\&G clerkship & 0.802 & & \\
\hline Interaction with O\&G interns/trainees & 0.788 & & \\
\hline Interaction with O\&G specialists/consultants/professors & 0.752 & & \\
\hline Hands-on experience in O\&G clerkship & 0.731 & & \\
\hline Interaction with midwives/O\&G nurses & 0.693 & & \\
\hline Compatibility with my interest/personality/skills & 0.516 & & \\
\hline Factor 2: working style & & 3.086 & 11.022 \\
\hline No. of years of on-site call & 0.894 & & \\
\hline On-call frequency & 0.862 & & \\
\hline Compatibility with work-life balance & 0.723 & & \\
\hline Level of urgency/stress in clinical work & 0.620 & & \\
\hline Factor 3: career prospects and influence from others & & 2.317 & 8.275 \\
\hline Advice from family & 0.767 & & \\
\hline Advice from seniors/teachers & 0.750 & & \\
\hline Prospect of promotion within Hospital Authority & 0.733 & & \\
\hline Prospect in private sector & 0.728 & & \\
\hline Popularity of O\&G among peers & 0.622 & & \\
\hline Compatibility with my religion & 0.413 & & \\
\hline
\end{tabular}

* $\mathrm{N}=228$, value of Kaiser-Meyer-Olkin measure of sampling adequacy: 0.833 ; Bartlett's test of sphericity: Chi squared statistics: 3093.25, degree of freedom: $378, P<0.00$ I

† $N=229$, value of Kaiser-Meyer-Olkin measure of sampling adequacy: 0.837; Bartlett's test of sphericity: Chi squared statistics: 3447.54, degree of freedom: $378, P<0.001$

influential factor for career interest in $O \& G$ with the interaction with O\&G specialists, consultants, highest percentage of variance explained (28.9\%). and professors, (4) hands-on experience in O\&G Included in this factor, five items had a higher clerkship, and (5) interaction with midwives and contribution with coefficients of above 0.6, namely O\&G nurses. This result is consistent with overseas (1) overall learning experience in O\&G clerkship, findings of the important influence of perception (2) interaction with $O \& G$ interns and trainees, (3) of clerkship, including interaction with O\&G staff, 
on career interest in O\&G. ${ }^{5,6}$ It emerges that $O \& G$ nurses, midwives, interns, trainees, and specialists play a vital role in ensuring a positive $O \& G$ clerkship experience.

Noticeably, this was the only key influential factor with a significant gender difference $(\mathrm{P}=0.021)$ : the clerkship experience of female participants had a more positive impact on their career interest in O\&G compared with males. The reason behind this phenomenon was beyond the scope of this study. Interestingly, Chang et $\mathrm{al}^{6}$ suggested that male medical students were more likely to increase their level of career interest in $O \& G$ during the clerkship. Assuming this finding is applicable to our local students, further study of gender difference in clerkship experience may help improve the imbalanced gender ratio of O\&G trainees. In our study, $126(54.1 \%)$ participants agreed that a more balanced gender ratio of staff would have a positive impact on career interest in $O \& G$.

It might be surprising to note that some items that might have been expected to be influentialsuch as interest in the specialty, ${ }^{10}$ compatibility with personality, and availability of training posts-were not among the key influential factors in this study.

There are several limitations of this study. First, recruitment of participants was affected by the attendance of medical graduates at the pre-internship lectures: $87.6 \%$ of all medical graduates. In addition, participation in this study was voluntary: 45 (15.9\%) of 283 medical graduates who attended the lectures did not participate. The reason for non-participation was not documented. There may be potential response bias as those with a low career interest in $O \& G$ may have been less keen to participate. Other possible reasons for non-participation were unwillingness to disclose career interest or uncertain career interest. A similar study may be conducted with interns towards the end of the internship when career interest is usually clearer. There may be possible changes in career interest and influential factors at another stage of career development. Some external factors, such as the availability of training posts at the time of application, may become more influential at this juncture. Second, the findings have weak generalisability as there are many external factors that change with time and may be different in different parts of the world. It may be useful to conduct similar study periodically to obtain an updated trend to facilitate manpower planning. Third, the items of possible influential factors included in the questionnaire were not exhaustive and were selected with reference to previous studies.

\section{Conclusions}

The study confirmed the observation of a low level of career interest in $O \& G$ among medical graduates and the decreasing popularity of $O \& G$ as a career choice.
Key influential factors for career interest in $O \& G$ and career choice included working style, clerkship experience, and career prospects. Encouragingly, there are modifiable elements among these factors, where improvement can be made by faculties, college, frontline staff, and hospital administrators.

\section{Acknowledgements}

We would like to thank Prof TP Lam and Dr Gilberto KK Leung, Institute of Medical and Health Sciences Education, Li Ka Shing Faculty of Medicine, The University of Hong Kong and Prof Tony KH Chung, Faculty of Medicine, The Chinese University of Hong Kong for their support and endorsement for this study to be conducted in the Faculties. We are grateful to Dr WC Leung, Chairman of Education Committee, The Hone Kong College of Obstetricians and Gynaecologists and the Chief of Service of our respective departments: Dr Anita Yeung, Prof Ernest HY Ng, and Dr TH Cheung, for their support. We would also like to acknowledge Dr Carmen KM Choi and Dr Daniel Wong for their helpful comments on the questionnaire.

\section{References}

1. Au Yeung SK. Impact of non-eligible person deliveries in obstetric service in Hong Kong. Hong Kong J Gynaecol Obstet Midwifery 2006;6:41-4.

2. Manpower requirement and strategies for doctors, Hospital Authority Administrative and Operational Meeting Paper No 693. Available from: http://www.ha.org. hk/haho/ho/cad_bnc/AOM-P693.pdf. Accessed 5 May 2015.

3. Posts available, Annual Recruitment Exercise for resident trainees 2015/16, Hospital Authority. Available from: http://www.ha.org.hk/ho/resident.htm. Accessed 5 May 2015.

4. Unfilled resident trainee post for Annual Recruitment Exercise 2015/16, Hospital Authority. Available from: http://www.ha.org.hk/ho/resident.htm. Accessed 3 Jul 2015.

5. Gariti DL, Zollinger TW, Look KY. Factors detracting students from applying for an obstetrics and gynecology residency. Am J Obstet Gynecol 2005;193:289-93.

6. Chang JC, Odrobina MR, McIntyre-Seltman K. Residents as role models: the effect of the obstetrics and gynecology clerkship on medical students' career interest. J Grad Med Educ 2010;2:341-5.

7. Fogarty CA, Bonebrake RG, Fleming AD, Haynatzki G. Obstetrics and gynecology-to be or not to be? Factors influencing one's decision. Am J Obstet Gynecol 2003;189:652-4.

8. Schnuth RL, Vasilenko P, Mavis B, Marshall J. What influences medical students to pursue careers in obstetrics and gynecology? Am J Obstet Gynecol 2003;189:639-43.

9. Lam TP. Specialty choice of medical graduates. Hong Kong Pract 1996;18:504-12.

10. Wu SM, Chu TK, Chan ML, Liang J, Chen JY, Wong SY. A study on what influence medical undergraduates in Hong Kong to choose family medicine as a career. Hong Kong Pract 2014;36:123-31. 